\title{
Ovariectomia visando à engorda de vacas de corte em confinamento
}

\author{
Ovariectomy in beef cattle, and their relationship with the fattening
}

\section{Cassia Regina de Paiva Carvalho ${ }^{[\mathrm{a}]}$, Camila Cristina Marcon ${ }^{[\mathrm{b}]}$, Luiz Ernandes Kozicki ${ }^{[\mathrm{c}]}$, Carlos Francisco Bueno Junior ${ }^{[b]}$, Carlos Eduardo Molli Pereira da Costa ${ }^{[b]}$}

[a] Bolsista do PIBIC, acadêmica do curso de Medicina Veterinária da Pontifícia Universidade Católica do Paraná (PUCPR), Curitiba, PR - Brasil, e-mail: casgat@terra.com.br

[b] Graduandos do curso de Medicina Veterinária da Pontifícia Universidade Católica do Paraná (PUCPR), Curitiba, PR - Brasil, e-mail: ccmarcon@hotmail.com.br; cfbuenojr@gmail.com; dudumpc@hotmail.com

[c] Docente do curso de Medicina Veterinária da Pontifícia Universidade Católica do Paraná (PUCPR), Curitiba, PR - Brasil, e-mail: kozicki.1@pucpr.br

\section{Resumo}

O presente estudo objetivou avaliar os efeitos da ovariectomia, em vacas de corte em confinamento, sobre o ganho de peso e rendimento de carcaça dos animais tratados. Foram selecionadas 100 fêmeas da raça Nelore submetidas a confinamento e divididas em dois grupos (G1 e G2) de 50 animais cada. No grupo G1, todos os animais foram submetidos à ovariectomia, sendo o grupo G2 o controle (não ovariectomizado). Todos os animais receberam idêntica alimentação e manejo e foram pesados nos dias: 0 (= início do tratamento), 46, 74 e 100, totalizando 100 dias do início do tratamento até o abate. Ao final do experimento, os dados demonstraram que os animais não ovariectomizados apresentaram maior ganho de peso e, consequentemente, maior ganho de peso diário em relação às vacas ovariectomizadas. O rendimento médio de carcaça quente no frigorífico não apresentou diferença significativa entre os grupos.

Palavras-chave: Ovariectomia. Vacas Nelore. Confinamento. Ganho de peso. Rendimento de carcaça.

\begin{abstract}
This research aimed to evaluate the effect of an ovariectomy on the Nelore cows, to check the weight gain and muscle conversion. A hundred females were selected from a Nellore breed, and separated into two groups (G1 and G2) of 50
\end{abstract}


animals. In the group $G 1$ all animals were ovariectomized, and the group $G 2$ was the control group. All the cows on days 0, 46, 74 and 100, performing 100 days between the beginning and the slaughter day were weighed. All the animals received the same nutrition and management during the experiment time. In conclusion, the cows no ovariectomized, showed greater weight gain and consequently greater daily weight gain than the cows ovariectomized. The muscle rate conversion, showed no significant difference between groups.

Keywords: Ovariectomy. Nelore. Confinement. Weight gain. Carcass profit.

\section{Introdução}

A ovariectomia em bovinos de corte para fins de engorda tem sido utilizada com muita frequência nos estados brasileiros produtores de carne bovina, porém, frequentemente tem sido debatida pelos profissionais da área da produção de carne. Os empresários do setor cárneo fazem apologia ao fato de que esse tipo de intervenção nos animais proporciona maior cobertura de gordura subcutânea, agregando desse modo melhor qualidade para a carne após refrigeração das carcaças (SILVA et al., 2006), contrapondo-se às opiniões divergentes de pecuaristas, os quais alegam que a castração inibiria o crescimento e resultaria em menor ganho de peso dos animais. Nesse contexto, discute-se o pressuposto do menor rendimento de carcaça das fêmeas não castradas em relação aos machos. Frequentemente, vacas de corte têm sido discriminadas pelas indústrias frigoríficas em virtude do menor retorno financeiro, conforme relatos de Crouse et al. (1989) e de Zobell, Goonewardene e Ziegler (1993).

Segundo Silva et al. (2004), a ovariectomia é utilizada em fêmeas bovinas de descarte, ou seja, animais considerados inaptos à reprodução ou mesmo em animais com irreversíveis anormalidades ovarianas, além de bezerras e novilhas jovens com baixa performance, descartadas da reprodução. Essa prática é utilizada inclusive com o intuito de valorizar os animais que, geralmente, seriam vendidos por um preço abaixo do valor de mercado. Ainda pairam dúvidas a respeito dos efeitos da ovariectomia em bovinos, levando-se em conta as características de carcaça. A castração de vacas, de acordo com Silva et al. (2004), objetiva tornar mais fácil o manejo do rebanho ao se eliminar as manifestações do estro e ao se incrementar o rendimento lácteo, bem como ao se executar terapias nos casos de ninfomania. Farias Jr. (2000) e Silva et al. (2006) relataram a eficácia da técnica da ovariectomia ao se inserir um anel de látex no pedículo ovariano, acarretando atrofia gonadal e encapsulamento ovariano, tornando os ovários afuncionais. Em função do exposto, o presente experimento objetivou verificar os efeitos da ovariectomia bilateral sobre os ganhos de peso das carcaças ao final de cem dias de confinamento em bovinos de corte.

\section{Material e método}

O experimento foi realizado na Fazenda Marcon, município de Poxoréo, no Estado do Mato Grosso. Foram selecionadas 100 vacas da raça Nelore destinadas ao confinamento para fins de engorda. Todos os animais foram submetidos a idênticas condições de nutrição e de manejo, em regime de semiconfinamento, alimentados com a forrageira Panicum maximum, e recebendo no cocho ração à base de resíduo de feijão, sorgo moído, além de sal mineral. Os animais foram divididos em dois grupos de 50 animais cada. O grupo G1 constituiu-se de vacas ovariectomizadas bilateralmente e o grupo G2 de fêmeas bovinas não ovariectomizadas.

A ovariectomia foi conduzida pelo método transvaginal (introdução da mão esquerda pela vagina, perfuração do fundo de saco vaginal e peritônio com bisturi de lâmina oculta, executando-se um orifício de modo a permitir a passagem inteira da mão para a captura dos ovários) e colocação de anel de látex no pedículo ovariano (lados direito e esquerdo) com o auxílio de um aparelho elaborado de tecnil, segundo técnica descrita por Silva et al. (2006). O aparelho foi modificado, constando de um cano medindo $10,0 \mathrm{~cm}$ de comprimento por 4,0 cm de diâmetro e haste maciça (40 cm de comprimento por 1,5 cm de diâmetro).

Rev. Acad., Ciênc. Agrár. Ambient., Curitiba, v. 8, n. 4, p. 405-408, out./dez. 2010 
O experimento teve duração de 100 dias. Os animais foram pesados no dia da colocação dos anéis de látex (dia da ovariectomia bilateral $=$ dia 0 ) e nos dias 46, 74 e 100. Por último foi pesada a carcaça quente no frigorífico. Os cálculos estatísticos foram realizados pelo o teste t de Student utilizando o software estatístico GraphPad Prism version 3.00 for Windows, San Diego Califórnia, EUA.

\section{Resultados e discussão}

Ao se verificar os dados da Tabela 1, observa-se que o grupo G1 (vacas ovariectomizadas) iniciou o experimento com peso médio (PM) maior que as fêmeas do grupo G2 (não ovariectomizadas). Visualiza-se que a variável ganho de peso médio (GPM) dos animais aponta maior ganho de peso em prol do G2, pois ao final dos 100 dias de experimento o G2 demonstrou 90,9 kg, ao passo que o G1 72,7 kg, diferenças essas significativamente diferentes. Diferenças significativas similares foram encontradas em prol dos animais não castrados relativamente ao ganho de peso médio diário (GPMD) (0,91 kg versus 0,73 kg do G1). Em trabalho semelhante, Chacur et al. (2007), ao pesquisarem os efeitos da ovariectomia sobre o ganho de peso, concluíram que a castração de novilhas promoveu significativo aumento de peso em regime de pasto, muito embora os animais tenham permanecido por 144 dias em confinamento, período esse bastante superior aos 100 dias, metodologia aplicada no presente experimento. Essa diferença pode ser atribuída ao maior período de confinamento dos animais.

Recentemente, Meirelles et al. (2007) executaram ovariectomia em novilhas meio-sangue europeu com meio-sangue zebuíno e observaram que o ganho de peso médio do grupo controle foi superior ao do grupo das fêmeas castradas, verificando-se 74,62 kg e $66,17 \mathrm{~kg}$, respectivamente, para os animais não castrados e castrados, no período de tempo de 56 dias de confinamento. Esses autores sugerem que um período maior que 56 dias de confinamento poderia exercer um efeito positivo sobre o ganho de peso e rendimento de carcaça dos animais tratados. Tal sugestão não pode ser comprovada, pois no presente experimento os animais permaneceram por 100 dias no confinamento após o tratamento, indicando que o confinamento na quantidade de dias utilizados não influenciou nos resultados. Cem dias de confinamento não foram suficientes para se observar melhoria de rendimento de carcaça. Segundo Chacur et al. (2007), animais em confinamento devem ser mantidos confinados em torno de 140 dias para se poder chegar a um diferente resultado, permitindo aos animais ovariectomizados mais tempo para uma resposta. Na presente pesquisa, o peso dos animais ao abate do grupo G1 (355,0 kg) foi maior do que o grupo dos animais não castrados, em função de que o peso inicial do grupo castrado era maior no dia zero (início dos estudos). No entanto, tanto o peso médio ao abate ( $p>0,05)$ quanto o rendimento médio de carcaça ( $>$ > 0,05) dos grupos não apresentou diferenças significativas, diferindo dos relatos de Silva et al. (2007), os quais obtiveram resultado semelhante na variável ganho de peso, mas diferindo quanto ao rendimento de carcaça.

Tabela 1 - Dados de peso médio, ganho de peso médio, ganho de peso médio diário e rendimento de carcaça em vacas de corte da raça Nelore submetidas à ovariectomia bilateral ( $\mathrm{n}=100)$, em Poxoréo, MT, em 2008

\begin{tabular}{lccccccc}
\hline & \multicolumn{7}{c}{ Dias após a ovariectomia (kg) } \\
\cline { 2 - 8 } & $\begin{array}{c}\mathbf{0} \\
\text { PM }\end{array}$ & $\begin{array}{c}\mathbf{4 6} \\
\mathbf{P M}\end{array}$ & $\begin{array}{c}\mathbf{7 4} \\
\mathbf{P M}\end{array}$ & $\begin{array}{c}\mathbf{9 9} \\
\text { PM }\end{array}$ & $\mathbf{G P M}$ & GPMD & MRC (\%) \\
\hline Grupo 1 (tratado) & 282,7 & 312,5 & 327,7 & 355,0 & $72,7 \mathrm{a}$ & $0,73 \mathrm{c}$ & 48 \\
Grupo 2 (controle) & 241,1 & 295,5 & 301,4 & 332,3 & $90,9 \mathrm{~b}$ & $0,91 \mathrm{~d}$ & 48 \\
\hline
\end{tabular}

Nota: $\mathrm{PM}=$ peso médio; $\mathrm{GPM}=$ ganho de peso médio; $\mathrm{GPMD}=$ ganho de peso médio diário; $\mathrm{MRC}=$ média do rendimento de carcaça. Letras diferentes na mesma coluna $=\mathrm{P}<0,001$.

Fonte: Dados da pesquisa.

Rev. Acad., Ciênc. Agrár. Ambient., Curitiba, v. 8, n. 4, p. 405-408, out./dez. 2010 


\section{Conclusão}

As vacas ovariectomizadas apresentaram menor ganho de peso no período de 100 dias de confinamento e, consequentemente, menor ganho de peso diário em relação às vacas não ovariectomizadas. $\mathrm{O}$ rendimento de carcaça quente no frigorífico não apresentou diferença significativa entre os grupos. Não se recomenda a ovariectomia em vacas visando à engorda pelo período de tempo empregado no presente experimento e, simultaneamente, sugere-se que esse tipo de experimento deva ser conduzido por período superior a 140 dias para se verificar possível ganho de peso, conforme relatos da literatura.

\section{Referências}

CHACUR, M. G. M. et al. Efeito da ovariectomia em novilhas Nelore x Angus, Bos taurus indicus x Bos taurus taurus sobre os ganhos de peso. Semina: Ciências Agrárias, v. 28, n. 2, p. 317-322, 2007.

CROUSE, J. D. Comparisons of Bos indicus and Bos taurus inheritance on carcass beef characteristics and meat palatability. Journal of Animal Science, v. 67, n. 8, p. 2661-2668, 1989.

FARIAS Jr., D. Efeitos da ovariectomia, aplicação de anel de látex no pedículo ovariano e dispositivo intrauterino no ganho de peso, características de carcaça e carne em novilhas e vacas destinadas ao abate. 2000. 59 f. Dissertação (Mestrado em Medicina Veterinária) - Faculdade de Ciências Agrárias e Veterinárias, Universidade Estadual Paulista, Jaboticabal, 2000.

MEIRELLES, C. et al. Avaliação do ganho de peso de novilhas ovariectomizadas por técnica transvaginal. Revista Acadêmica: Ciências Agrárias e Ambientais, v. 5, n. 3, p. 303-307, 2007.

SILVA, L. A. F. et al. Descrição de duas técnicas cirúrgicas para castração de fêmeas bovinas e avaliação do pós-operatório. Ciência Animal Brasileira, v. 5, n. 1, p. 49-54, 2004.

SILVA, L. A. F. et al. Anel de látex aplicado no pedículo ovariano de bezerras Nelore. Acta Scientiarum. Animal Science, v. 28, n. 1, p. 97-103, 2006.

SILVA, L. A. F. et al. Características de carcaça e carne em novilhas castradas ou não-castradas da raça Nelore. Ciência Animal Brasileira, v. 8, n. 4, p. 777-785, 2007.

ZOBELL, R. D.; GOONEWARDENE, L. A.; ZIEGLER, C. B. K. The effects of spaying and anabolic implants on average daily weight gain of heifers on pasture. Canadian Veterinary Journal, v. 34, n. 5, p. 727-730, 1993.

Recebido: 24/03/2010

Received: 03/24/2010

Aprovado: $12 / 08 / 2010$ Approved: 08/12/2010 